months after operation, the patient was well and did not have further psychiatric symptoms. Pyridostigmine bromide was discontinued, and computed tomographic scan did not reveal any signs of recurrent tumor.

It has been estimated that ectopic thymic tissue in the neck has an incidence as high as $21.0 \%,{ }^{2}$ but thymoma arising from undescended cervical thymus is exceedingly rare. To the best of our knowledge, fewer than 10 cases of true cervical thymoma have been previously reported. The diagnosis of aberrant cervical thymus or thymoma is rarely made before operation. Awareness of this entity and the need for as complete as possible removal of thymic tissue compel the surgeon to perform a meticulous neck dissection in all myasthenic patients, with or without known thymoma.

The association of myasthenia gravis and other autoimmune disorders with thymoma has been usually described in the form of isolated reports. Although in most of these reports the extent of the procedure has not been clearly described, thymectomy has been reported as effective for control of myasthenia gravis but failing to improve the clinical course of the other associated diseases. ${ }^{3-5} \mathrm{We}$ believe, however, that even in immune-mediated disorders other than myasthenia gravis extended and meticulous surgical resection could result in good remission rates.

\section{REFERENCES}

1. Jaretzki A 3rd, Wolff M. "Maximal" thymectomy for myasthenia gravis: surgical anatomy and operative technique. J Thorac Cardiovasc Surg 1988;96:711-6.

2. Yamashita H, Murakami N, Noguchi S, et al. Cervical thymoma and incidence of cervical thymus. Acta Pathol Jpn 1983;33:189-94.

3. Monden Y, Uyama T, Nakahara K, et al. Clinical characteristics and prognosis of myasthenia gravis with other autoimmune diseases. Ann Thorac Surg 1986;41: 189m-92.

4. Gibson LE, Muller SA. Dermatologic disorders in patients with thymoma. Acta Derm Venereol (Stockh) 1987;67:351-6.

5. Levasseur P, Menestrier M, Gaud C, et al. Thymomes et maladies associées: a propos d'une série de 255 thymomes opérés. Rev Mal Resp 1988;5: $173-8$.

\title{
PURULENT PERICARDITIS: REDISCOVERY OF AN OLD REMEDY
}

Daniel D. M. Mann-Segal, MBBS, E. Anne Shanahan, BSc, MBBS, FRACS, LLB, Bruce Jones, MBBS, FRACS, and Day Ramasamy, MRCP, DA, DCH, Melbourne, Victoria, Australia

The mortality rate for untreated purulent pericarditis is almost $100 \%$. Treatment of choice today is a combination of drainage and intravenous antibiotics. The mode of optimum drainage remains controversial. Aspiration alone, wide-bore pericardotomy, operative evacuation with pericardectomy, and subxiphoid drainage alone or with irrigation have all been advocated as treatments of first choice for both simple and loculated purulent pericarditis. $^{1}$

Subxiphoid pericardial irrigation with streptokinase and streptodornase was first documented more than 40 years ago. ${ }^{2,3}$ Despite its universal success, this treatment has been largely overlooked. We report the revival of this approach and describe its potential as a conservative option, particularly for the loculated condition.

A 76-year-old man sought treatment for mild exertional dyspnea. A $2 \mathrm{~cm}$ lingular lesion consistent with carcinoma was discovered by chest radiography, and he was hospitalized for further investigation. Physical examination

From the Thoracic Surgery and Intensive Care Units of Dandenong Hospital, Melbourne, Victoria, Australia.

Accepted for publication July 27, 1995.

J THORAC CARdiovasc Surg 1996;111:487-8

Copyright (C 1996 by Mosby-Year Book, Inc.

$0022-5223 / 96 \$ 5.00+0 \quad \mathbf{1 2 / 5 4 / 6 8 1 9 9}$ revealed fine bibasal crepitations. Electrocardiography showed left bundle branch block. Results of bronchoscopy were unremarkable. Two percutaneous lingular biopsies were carried out under computed tomographic guidance. Histologic examination was inconclusive, revealing " $a b$ normal cells suggestive of malignancy." Thoracotomy was performed and the lingular lobe was resected. Histologic preparation revealed a hamartoma.

Clinical biventricular failure developed on the eighth postoperative day. Chest radiography revealed cardiomegaly and pulmonary veinous congestion. An echocardiogram demonstrated a $3 \mathrm{~cm}$ wide pericardial effusion incorporating isolated "shaggy zones" consistent with fibrin deposition. The patient remained afebrile, but his leukocyte count rose to 26,000 cells/ml. Two attempts at paracentesis failed to aspirate any fluid before entering the myocardium. Subsequent ultrasonographically guided aspiration produced a hemoserous discharge of only $3 \mathrm{ml}$, which grew a multiply sensitive Staphylococcus aureus isolate. The patient's condition continued to deteriorate despite appropriate antibiosis and increasing ionotropic support. A further echocardiogram confirmed tamponade.

By this stage open drainage was no longer safe. A 7F pericardiocentesis tube was therefore inserted through a subxiphoid approach. This initially resulted in no drainage. A combination of 100,000 units of streptokinase with 
25,000 units of streptodornase in $20 \mathrm{ml}$ of normal saline solution was then infiltrated every 8 hours, alternating with flucloxacillin ( $2 \mathrm{gm}$ in $20 \mathrm{ml}$ of normal saline solution) at the 4-hour interval. The tube was clamped immediately after infiltration for 1 hour and then allowed to drain for the next 3 hours. At the end of 24 hours, $800 \mathrm{ml}$ of purulent fluid had been drained; at the end of 48 hours, a further $1200 \mathrm{ml}$ had been drained. This protocol was followed for a week, by which time the collection had been totally evacuated and the echocardiogram had returned to normal.

The patient subsequently acquired Pseudomonas pneumonia, followed by adult respiratory distress syndrome and hepatorenal failure. With intensive therapy and time, these problems resolved. The patient was rehabilitated and discharged to his home, well and active, $41 / 2$ months after his initial admission.

At the time of treatment, we were unaware of the previous use of streptokinase and streptodornase for lavage in purulent pericarditis, although we did have experience with this combination in infected pneumonectomy spaces. Streptokinase acts by activating the fibrinolytic system and brings about dissolution of blood clots and the fibrinous component of exudates. Streptodornase liquefies the viscous nucleoprotein of pus. ${ }^{2,3}$ Drainage is facilitated by the liquefaction of the two main viscous substances produced by the infectious or inflammatory processes. Exposure to locally infiltrated antibiotics is thereby enhanced.

We believe that the initial postoperative aspirations failed because of the thickness, tenacity, and partial loculation of the pericardial fluid. This was confirmed by echocardiography and reflects the findings of Morgan and colleagues, ${ }^{4}$ who found the consistency of the purulent material in purulent pericarditis often "similar to that of scrambled eggs."

Recent literature has discussed the efficacy of pericardial lavage with either saline solution and antibiotics or povidone iodine. The main source of concern with this method appears to be its inefficacy in the case of thick adhesions and loculi. ${ }^{1,4,5}$ Other studies by Cheatham and coworkers $^{6}$ and Cosgrove, Echeverria, and Sade ${ }^{7}$ reflect the need for operative intervention in a high percentage of cases as a result of failure of pericardiocentesis and to avoid pericardial constriction and intrapericardial abscess loculation. The presence of fibrinous clots found posterior to the heart, accessible by thoracotomy alone, led Majid and $O$ Omar $^{1}$ to recommend surgical drainage and pericardectomy universally in purulent pericarditis. They did not, however, take into account the full body of evidence supporting the role of streptokinase and streptodornase lavage in loculated purulent pericarditis.

In 1984 Bennett $^{8}$ suggested streptokinase irrigation in the case of the thick, fibrinous exudates of Haemophilus influenzae purulent pericarditis described by Morgan and colleagues. ${ }^{4}$ Bennett ${ }^{8}$ reported success in two such cases. Responses indicated that the technique was promising but anecdotal and requiring further documentation. It is noteworthy that all parties were unaware that this method had been established more than 30 years previously by five teams, who were also largely unaware of each other's work.

Between 1951 and 1955, five individual cases were documented in which purulent pericarditis was treated by intrapericardial administration of streptokinase and streptodornase, either alone or in combination with antibiotics. ${ }^{2,3,9-11}$ After Lundstrom's 1955 article, ${ }^{11}$ the technique seems to have been neglected. This is somewhat surprising in view of the successful outcome in all reported cases without significant adverse reactions or the need for any further intervention. Self-limiting fever and malaise several hours in duration were the only documented side effects. The technique was empirically rediscovered by Bennett ${ }^{8}$ in 1984 and again recently by our group.

Bennett ${ }^{8}$ did not document the presence or absence of any complications but did indicate successful outcomes. Our patient also recovered well but had a prolonged and difficult course. His medical problems are not among those previously associated with streptokinase and streptodornase administration, however, and are not uncommon problems in older, decompensating patients in an intensive care unit.

At least eight patients in the past 44 years have been treated for purulent pericarditis with streptokinase and streptodornase infusions, with universally successful outcomes. This cure rate for a disease process with such significant mortality is encouraging. We believe that the treatment represents a safe, conservative management option for purulent pericarditis and warrants consideration as first-line therapy for the loculated form.

\section{REFERENCES}

1. Majid AA, Omar A. Diagnosis and management of purulent pericarditis: experience with pericardiectomy. J Thorac Cardiovasc Surg 1991;102:413-7.

2. Goldsmith R, Sterling JA. Debridement using catalytic enzymes. Am Pract 1951;2:858-62.

3. Wright LT, Smith DH, Rothman M, Metzger WI, Quash ET. Use of streptokinase-dornase in certain surgical conditions. J Int Coll Surg 1951;15:286-98.

4. Morgan RJ, Stephenson LW, Woolf PK, Edie RN, Edmunds LH. Surgical treatment of purulent pericarditis in children. J THORAC CARDIOvasc Surg 1983; 85:527-31.

5. Thavendrarajah V, Ghia PS, Kozinn W, Little T. Catheter lavage and drainage of pneumococcal pericarditis. Cathet Cardiovasc Diagn 1993;29:322-4.

6. Cheatham JE, Grantham RN, Peyton MD, et al. Hemophilus influenzae purulent pericarditis in children: diagnostic and therapeutic considerations. J Thorac Cardiovasc Surg 1980;79:933-6.

7. Cosgrove DM, Echeverria P, Sade RM. The management of Haemophilus influenzae type $\mathrm{B}$ pericarditis. Ann Thorac Surg 1976;21:281-3.

8. Bennett EV. Purulent pericarditis. J Thorac CardroVASC SURG 1984;87:641-2.

9. Roy BB. Purulent pericarditis treated with streptokinase-streptodornase. J Indian Med Assoc 1954;24:264-5.

10. Adie GC, Childress WG. Experiences with streptokinase and streptodornase. Ann Surg 1951;134:659-71.

11. Lundstrom R. Purulent pericarditis and empyema caused by Haemophilus influenzae, type B. Am Heart J 1955;49:108-15. 